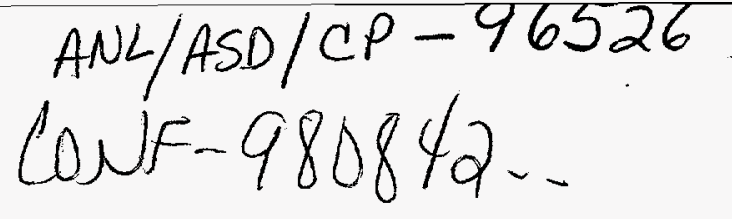

Optical Techaiqques for Electron-Beam Characterizations on the APS SASE FEL Project *

\author{
A. H. Lumpkin, B. X. Yang, W. J. Berg, M. White, J. W. Lewellen, \\ and S.V.Milton \\ Advanced Photon Source \\ Argonne National Laboratory \\ Argonne, IL 60439 USA
}

At the Advanced Photon Source (APS) the injector linac's DC thermionic gun is being supplemented by a low-emittance if thermionic gun that will support the SASE FEL project. To address the anticipated smaller beam sizes, the standard Chromox beam-profiling screens are being complemented by optical transition radiation (OTR) and Ce-doped YAG single-crystal converters. Direct comparisons of the effective conversion efficiency, spatial resolution, and time response of the three converter screen types have been performed using the DC thermionic gun's beam accelerated to 400 to $650 \mathrm{MeV}$. An apparent blurring of observed beam size with increasing incident charge areal density in the YAG crystal was observed for the first time. Only the OTR was prompt enough for the few-ps domain micropulse bunch length measurements performed with a streak camera. Initial beam images of the rf-thermionic gun beam have also been obtained.

* Work supported by the U.S. Department of Energy, Office of Basic Energy Sciences, under Contract No. W-31-109-ENG-38.

\title{
MASTER yr
}

DHTIRIBUTHON OF THSS COCUMENT IS LNLMITED

The submitted manuscript has been created by the University of Chicago as Operator of Argonne National Laboratory ("Argonne") under Contract No. W-31-109-ENG-38 with the U.S. Department of Energy. The U.S. Government retains for itself, and others acting on its behalf, a paid-up, nonexclusive. irrevocable worldwide license in said article to reproduce, prepare derivative works, distribute coples to the public, and perform publicly and display publicly, by or on behalf of the Government. 


\section{DISCLAIMER}

This report was prepared as an account of work sponsored by an agency of the United States Government. Neither the United States Government nor any agency thereof, nor any of their employees, makes any warranty, express or implied, or assumes any legal liability or responsibility for the accuracy, completeness, or usefulness of any information, apparatus, product, or process disclosed, or represents that its use would not infringe privately owned rights. Reference herein to any specific commercial product, process, or service by trade name, trademark, manufacturer, or otherwise does not necessarily constitute or imply its endorsement, recommendation, or favoring by the United States Government or any agency thereof. The views and opinions of authors expressed herein do not necessarily state or reflect those of the United States Government or any agency thereof. 


\section{DISCLAIMER}

Portions of this document may be illegible in electronic image products. Images are produced from the best available original document. 


\section{Introduction}

The higher brightness beams needed for a self-amplified spontaneous emission (SASE) freeelectron laser (FEL) injector linac require enhanced characterization capability as well [1]. At the Advanced Photon Source (APS) we are addressing the issue with adjustments to the optical techniques used for electron beam characterizations on the injector linac. The original DC thermionic gun is being supplemented by a low-emittance rf thermionic gun [2]. The original Chromox beam profiling screens are being complemented by the addition of optical transition radiation (OTR) and Ce-doped YAG single-crystal converters at selected positions. Both of these latter converters show better spatial resolution and temporal response than the Chromox screens. However, only the OTR mechanism is prompt enough to support streak camera measurements on the few-ps micropulse bunch length. In the course of these direct screen comparisons with OTR as the common reference, we observed for the first time an apparent "blurring" of beam image size in the YAG converter with increasing charge areal density. These conditions were achieved with a 30-nslong macropulse involving only a few $\mathrm{nC}$ from the $\mathrm{DC}$ thermionic gun accelerated to $600 \mathrm{MeV}$. Since we had an elongated beam focus with a 10 to 1 aspect ratio, the charge areal density was reduced for a given incident charge in these experiments. These results are relevant to emerging SASE FEL projects where electron beam quality is critical.

\section{Experimental Background}

The APS facility's injector system uses a 250-MeV S-band electron linac and an in-line Sband $450-\mathrm{MeV}$ positron linac. The primary electron gun is a conventional $\mathrm{DC}$ thermionic gun. For one alternate configuration, an $\mathrm{rf}$ thermionic gun, designed to generate low-emittance beams $(<5$ $\pi \mathrm{mm}$ mrad) and configured with an $\alpha$ magnet, injects beam just after the first linac accelerating 
section [3]. Then both in-line linacs can be phased to produce $100-$ to $650-\mathrm{MeV}$ electron beams when the positron converter target is retracted.

The if gun's projected, normalized emittance at higher peak current is about an order of magnitude lower than that expected of the DC gun, and correspondingly smaller beam spot sizes should result. The standard intercepting screens are based on Chromox of 0.25 -mm thickness (rotated $45^{\circ}$ to the beam) and with a 300 -ms decay time. Previous experiences on the Los Alamos linac-driven FEL with a low-emittance photoelectric injector (PEI) support the applicability of optical transition radiation (OTR) screens oriented at $45^{\circ}$ to the beam direction for profiling small beams [4]. In addition, we have installed a Ce-doped YAG single crystal of $0.5 \mathrm{~mm}$ thickness normal to the beam direction with a polished metal mirror at $45^{\circ}$ to the beam just behind it. The OTR screen and the YAG-mirror assembly are on two separate actuators on orthogonal faces of a beamline cubic-shaped cross. The light is transported out of the tunnel via two $150-\mathrm{mm}$ diameter achromat lenses to an optics table. The OTR or YAG light is viewed by a charge-coupled device (CCD) camera; a charge-injection device (CID) camera; a gated, intensified CCD camera; and a Hamamatsu C5680 dual-sweep streak camera. The most useful vertical sweep plug-in has been a synchroscan unit phase-locked to $119.0 \mathrm{MHz}$, the 24th subharmonic of the $2856 \mathrm{MHz}$ linac frequency. A low-jitter countdown circuit has been built using Motorola ECLIN PS logic to generate the 24th subharmonic. It has been tested with a 0.7 -ps (rms) jitter pulse generator, and the total jitter was observed to be $1.1 \mathrm{ps.} \mathrm{Bandpass} \mathrm{filters} \mathrm{on} \mathrm{the} \mathrm{output} \mathrm{result} \mathrm{in} \mathrm{a} \mathrm{clean} 119.0-\mathrm{MHz}$ sine wave to be used with the synchroscan unit [5].

The initial tests of the optical diagnostics have been done with a beam from the DC gun. These were done mostly in the $500-$ to $600-\mathrm{MeV}$ region with 2 to $5 \mathrm{nC}$ in the macropulse com- 
prised of 86 micropulses. Recently the rf gun beam was imaged on the upstream beamline locations and at the end of the linac.

3. Experimental Results

We will report results on both transverse and longitudinal aspects of the electron beam.

\subsection{Transverse Measurements}

In our preliminary results using an in-tunnel camera, we initially compared the smallest beam sizes we could observe on half Chromox/half Ti OTR foil [6]. From these measurements we deduced the Chromox limiting resolution of $\sigma \approx 200 \mu \mathrm{m}$ since the OTR screen provided much better resolution.

In this paper we focus our attention more on the comparisons of the YAG-mirror assembly and the OTR screen. There have been previous reports on the achievement of high spatial resolution comparable to OTR screens, with about 1000 times more visible light emitted and with a response time of $80 \mathrm{~ns}$ (FWHM) [7]. Those measurements were done with a PEI beam accelerated to $50 \mathrm{MeV}$ using about $0.1 \mathrm{nC}$ of charge in a single micropulse. In our studies we have used 500- to $600-\mathrm{MeV}$ beams and a 30-ns-long macropulse comprised of 86 micropulses. The macropulse average current of $8 \mathrm{~mA}$ corresponds to about $250 \mathrm{pC}$. We have taken data at macropulse currents up to $625 \mathrm{~mA}$. However, in Fig. 1 we show an OTR image at $100 \mathrm{~mA}(\sim 3 \mathrm{nC})$ with a horizontal profile size $180 \mu \mathrm{m}$ (FWHM), or $\sim 76 \mu \mathrm{m}(\sigma)$, and an aspect ratio $(\mathrm{H} / \mathrm{v})$ of $1 / 3$. In Fig. 2 we show an image from the YAG screen with additional neutral density filter and a bandpass filter to compensate for the YAG brightness. In this case, the best focus we could obtain horizontally was 45\% larger at $286 \mu \mathrm{m}(\mathrm{FWHM})$ and an aspect ratio $\left({ }^{\mathrm{H}} / \mathrm{v}\right)$ of $1 / 3$.

Subsequently, we have done a more controlled series of measurements as a function of beam

current. In this case the aspect ratio $(\mathrm{H} / \mathrm{V})$ of $1 / 10$ was used. We carefully adjusted the camera posi- 
tion on a rail to compensate for the displacement of the YAG crystal from the OTR $45^{\circ}$ plane in the object distances for each current. We also adjusted the neutral density filter used between YAG and OTR for the increasing current. As shown in Table 1 and Fig. 3, the horizontal image sizes of $70-80 \mu \mathrm{m}$ (FWHM), or 30-35 $\mu \mathrm{m}(\sigma)$, were achieved at 30 and $60 \mathrm{~mA}$ for both screens, but at 100 $\mathrm{mA}$ and above, the observed beam image sizes increased much faster with current using the YAG crystal than using the OTR screen. These data suggest a saturation or blooming phenomenon in the YAG crystal at higher incident areal charge densities. The 33\% increase in observed beam size from the YAG:Ce at $150 \mathrm{~mA}$ (or $4.7 \mathrm{nC}$ ) occurred when a $40 \times 400 \mu \mathrm{m}^{2}$ spot size was seen on the OTR screen. At $625 \mathrm{MeV}$, the charge areal density of about $0.3 \mathrm{pC}$ per $\mu \mathrm{m}^{2}$ appears to be sufficient for the effect to be detected, and this would indicate reason for concern for $0.5 \mathrm{nC}$ focused into a $20 \times 20 \mu \mathrm{m}^{2}$ spot. In an initial beam size measurement with $170 \mathrm{~mA}$ from the rf gun at a beam energy of $400 \mathrm{MeV}$ and at the $140 \times 140 \mu \mathrm{m}^{2}$ spot size (as observed with OTR), the YAG:Ce image also was larger. We still need to test this phenomenon further with lower-emittance beams and search for alternative explanations.

\subsection{Longitudinal Measurements}

The evaluation of DC gun micropulse bunch length was also done using the streak camera. Previous measurements have been done with an if phasing technique [8].

In Fig. 4 we show the synchroscan image of the 4 micropulses from the 86 micropulses in the macropulse. This synchronous sum has low jitter $(<1 \mathrm{ps})$, and by using the bandpass filter any chromatic temporal dispersion effects were also reduced. The observed bunch length was about 4.4 ps (FWHM), or $1.9 \pm 0.2 \mathrm{ps}(\sigma)$, in good agreement with the $2.2 \pm 0.1 \mathrm{ps}$ of Reference 8 . The resolution is about $0.6 \mathrm{ps}(\sigma)$. In Fig. 5 a very graphic example of the slower response time of the 
YAG crystal is shown. The vertical band of light from the scintillator's decay completely obscures the few-ps time domain.

In Fig. 6 a dual-sweep streak image is shown at a macropulse average beam current of 625 $\mathrm{mA}$. The 100 -ms horizontal time axis displays separately the macropulses arriving at 30 -ms intervals. The micropulse bunch length of $4.9 \mathrm{ps}$ (FWHM) at $0.22 \mathrm{nC} /$ micropulse implies a peak current of about $45 \mathrm{~A}$.

\subsection{RF Gun Accelerated Beam}

In August 1998, initial images were obtained of the rf gun beam at 50-MeV, 150-MeV, and $400-\mathrm{MeV}$ stations. Preliminary measurements using the streak camera for the beam at $400 \mathrm{MeV}$ indicated a bunch length of one un-optimized beam of 8-10 ps (FWHM).

\subsection{Summary}

In summary, optical techniques have been developed for electron beam measurements within the APS SASE project. The OTR and Ce-doped YAG crystals provide a trade on conversion efficiency, response time, and spatial resolution that cover the near-term needs of the project. The techniques have been validated in the DC thermionic gun beam, and initial measurements on the If thermionic gun beam have been performed. 
Table 1: Comparison of Beam Spot Sizes Using the YAG and OTR Converter Screens (June '98 Data)

\begin{tabular}{|c|c|c|c|}
\hline Converter & ND Filter & $\mathrm{I}_{\mathrm{B}}(\mathrm{mA})$ & $\begin{array}{c}\text { X-Size } \\
(\mathrm{FWHM})(\mu \mathrm{m})\end{array}$ \\
\hline \hline OTR & 0.0 & 30 & $90 \pm 7$ \\
YAG & 2.0 & 30 & $77 \pm 7$ \\
\hline OTR & 0.5 & 60 & 68 \\
YAG & 2.5 & 60 & 70 \\
\hline OTR & 0.8 & 107 & 84 \\
YAG & 2.8 & 107 & 114 \\
\hline OTR & 0.8 & 150 & 95 \\
YAG & 2.8 & 150 & 125 \\
\hline OTR & 1.0 & 220 & 103 \\
YAG & 2.8 & 220 & 205 \\
\hline
\end{tabular}

The aspect ratio $\mathrm{H} / \mathrm{V}$ was $\sim 1 / 10 . \mathrm{ND}=0.3$ is a factor of 2 in attenuation. 


\section{References}

[1] Alex H. Lumpkin, "On the Path to the Next Generation of Light Sources," Nucl. Instrum. Methods in Phy. Res., A393, 147-151 (1997).

[2] M. Borland, “An Improved Thermionic Microwave Gun and Emittance Preserving Transport Line," Proc. 1993 Particle Accelerator Conference, Washington, DC, May 17-20, 1993, 30153017 (1993).

[3] S. V. Milton, et al., "The Advanced Photon Source Low-Energy Undulator Test Line," Proc. of the 1997 Particle Accelerator Conference, Vancouver, B. C. , May 12-16, 1997 (to be published). [4] A. H. Lumpkin, et al., "Nucl. Inst. and Meth. A296, 769-775 (1990).

[5] R. Laird and F. Lenkszus, Argonne National Laboratory, private communication, April 1997. [6] A. H. Lumpkin, W. J. Berg, and B. X. Yang, "Planned Optical Diagnostics for the APS LowEnergy Undulator Test Line," Proc. of the 1997 Particle Accelerator Conference, Vancouver, B. C., May:12-16, 1997 (to be published).

[7] W: S. Graves, R. D. Johnson, and P. G. O'Shea, “A High Resolution Electron Beam profile Monitor," idem (to be published).

[8] N. Sereno, et al., "Bunch Length Measurements at the Advanced Photon Source (APS) Linear Accelerator," Proc. of the 1995 Particle Accelerator Conference, Vol. 2, 1070-1072 (1996). 


\section{Figure Captions}

Fig. $1 \mathrm{CCD}$ camera beam image at $600 \mathrm{MeV}$ and $100 \mathrm{~mA}$ using the OTR screen.

Fig. 2 CCD camera beam image at $600 \mathrm{MeV}$ and $100 \mathrm{~mA}$ using the YAG:Ce single-crystal converter. The observed size appears larger than that of Fig. 1.

Fig. 3 Plot of the observed beam size versus macropulse average current for the YAG:Ce (solid circles) and the OTR (solid squares) converter screens. An image size growth for the YAG data relative to the OTR data is seen with increasing current beyond $60 \mathrm{~mA}$.

Fig. 4 Synchroscan streak camera image of the linac micropulses using the OTR mechanism. The if phase delay is such that some micropulses are seen on the up sweep and some on the down sweep of the $119.0 \mathrm{MHz}$ sinusoidal deflection. The observed bunch length is about $4.4 \mathrm{ps}$ (FWHM) including the about $1.6 \mathrm{ps}$ (FWHM) limiting resolution contribution.

Fig. 5 Synchroscan streak camera image of the linac micropulse using the YAG single crystal. All micropulse bunch length detail is obscured by the 80-ns response time of the crystal. This results in the vertical band filling the fast time axis.

Fig. 6 Dual-sweep synchroscan images of the linac pulse. The horizontal axis is $100 \mathrm{~ms}$ and shows the 30-ms separation of the macropulses. The micropulse average bunch length is 4.9 ps (FWHM). 


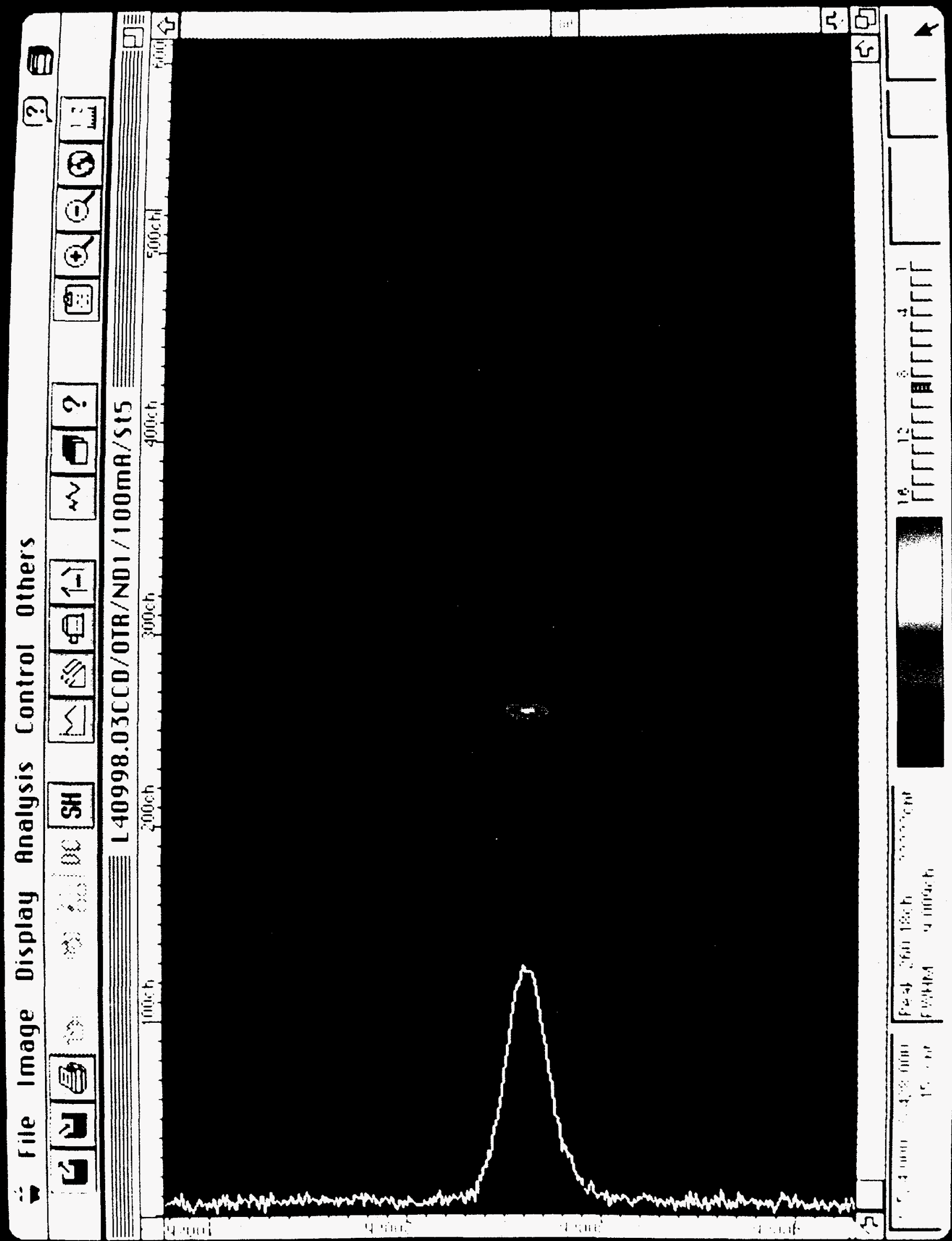




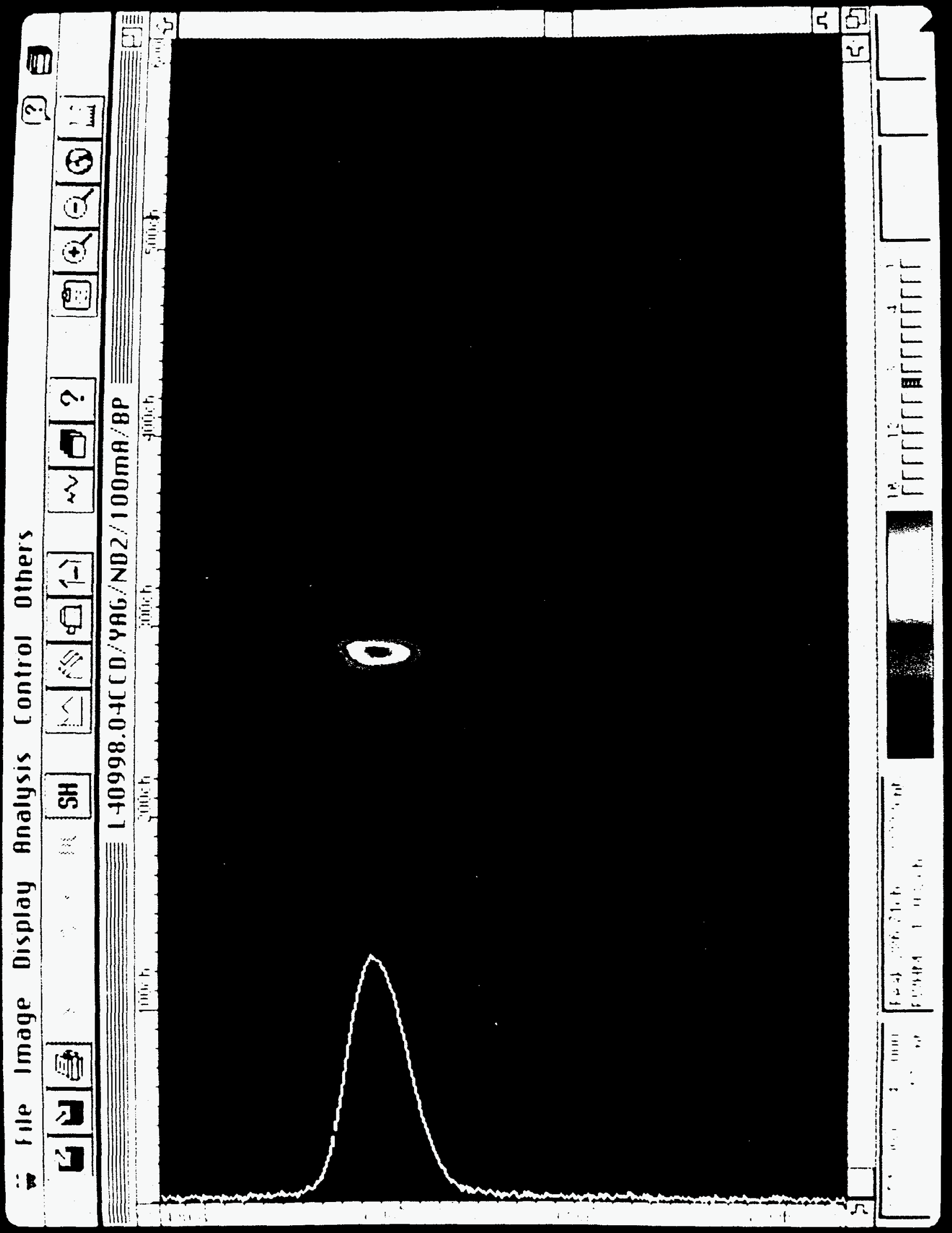




\section{MEASURED BEAM SIZE VS. BEAM CURRENT}

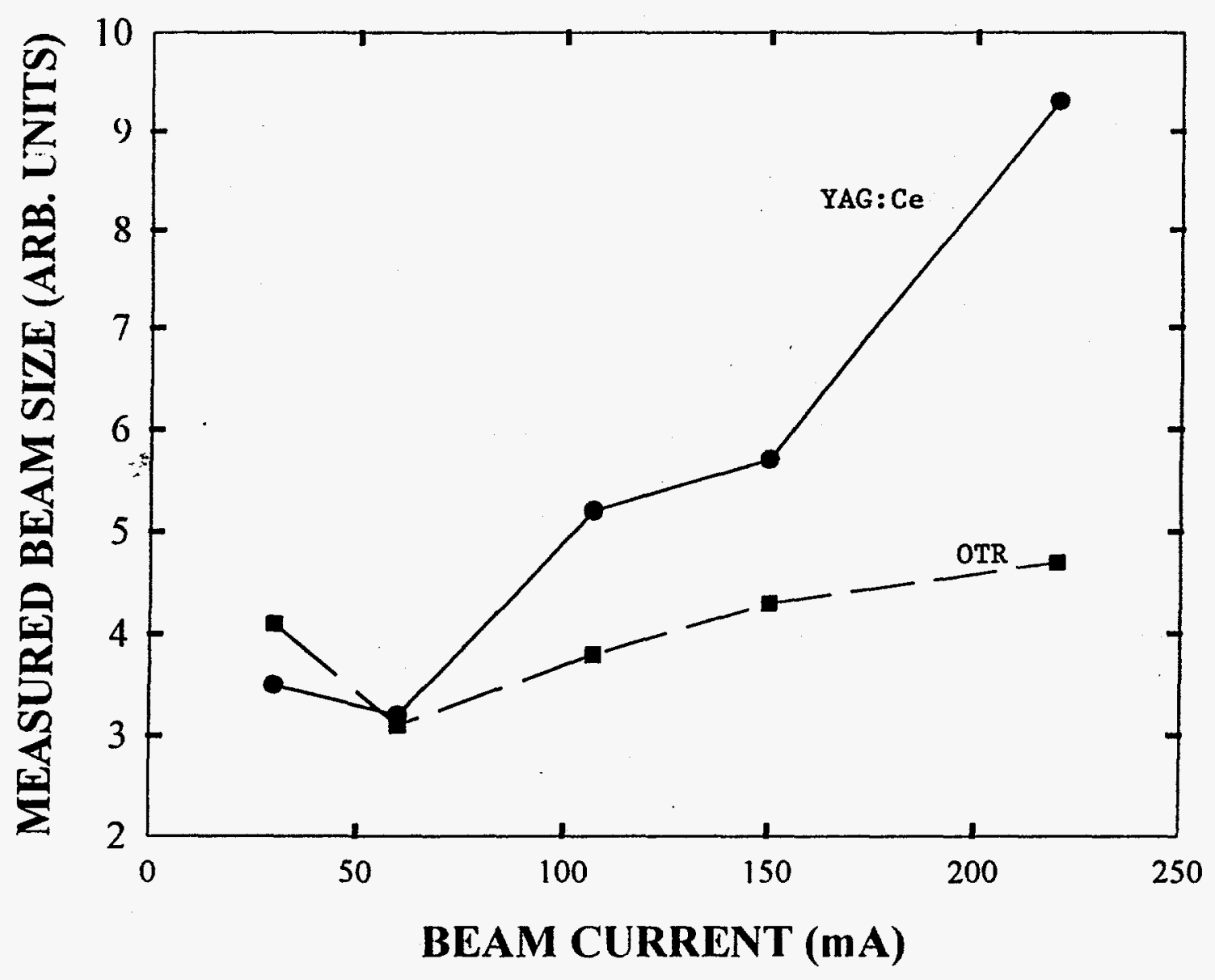

F18. 3

A. H. Lumpkin 


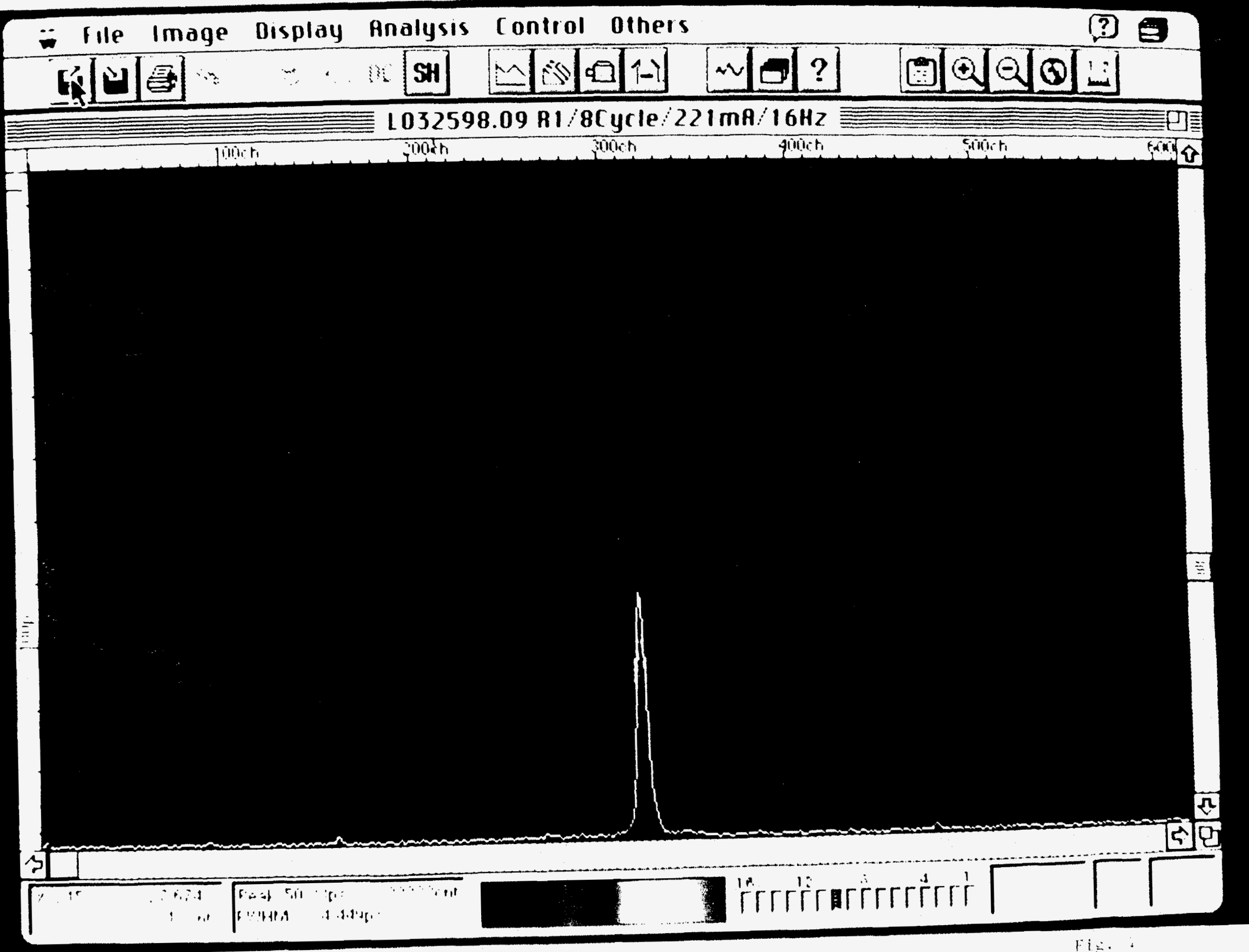




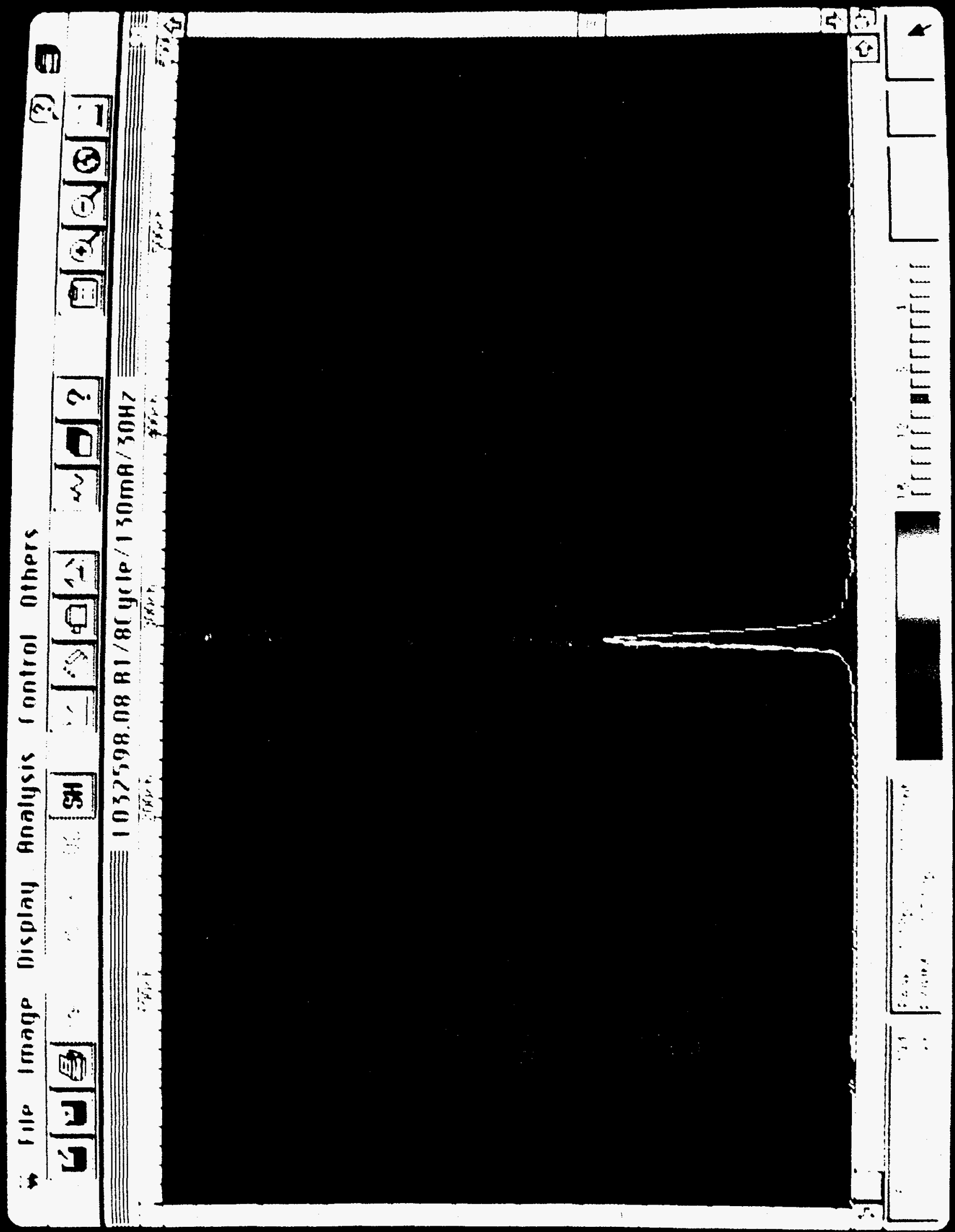




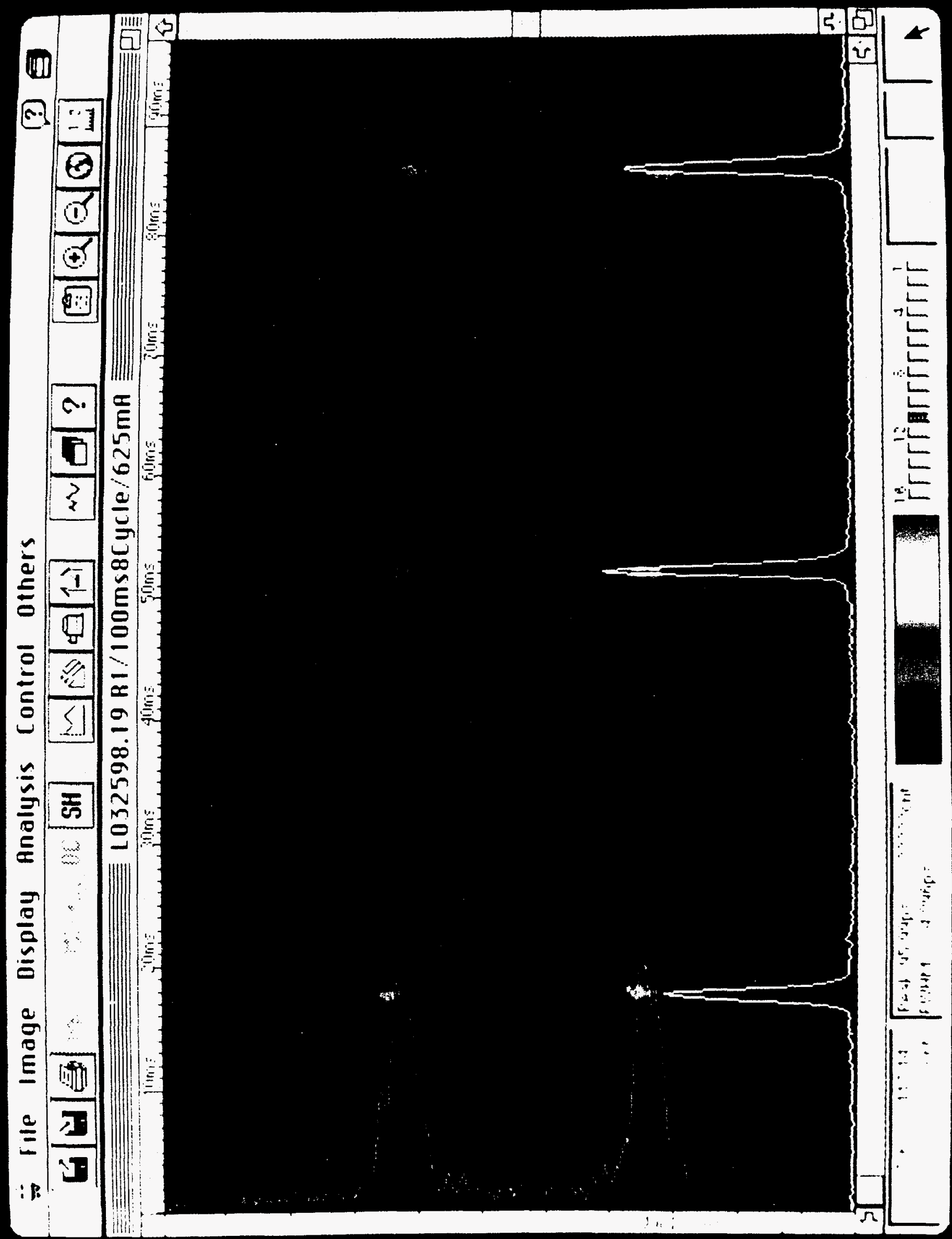

